to husbands he wrote: "Fill your wife's stomach and clothe her back, and her love shall reward you, as a well-tilled estate rewards the cultivator." Even in those far-off days, six thousand years ago, woman looms large on the family horizon. While the sex of the little demons that harass the lives of the small-headed peoples is doubtful, the deities presiding over the fortunes of the bigger-headed races of the ancient Eastern world were as a rule both bisexual and anthropomorphous. The male element, Khëen-yang, of China and India, originating in a solar myth, ascribed to a god both generative and destructive powers; the recurrent dryness of summer often destroying the springtide fertility of the moist earth. ${ }^{12}$ Yet it is around the female element that the main interest centres. Throughout the Eastern world for many centuries the goddess of love and fertility, Kwan Yin, the "Turanian Venus" of China and Japan, and her child, Zen-Zai, embodied the solar nymphean myth above mentioned. The goddess has been identified at different times and by various nations as the Assyrian Semiramis, Astarte, and Ishtar, goddess of love and chase, the Persian Anaitis, and later in Europe as Aphro: dite, Artemis, Juno, and Venus. She was subsequently associated with the cult of the Virgin Mary.

\section{The Birth of Altruism and the Development of} Conscience, and Scapegoats.

Love of offspring and preservation of racial characters are the bases upon which the attractive presentment of a spirit of universal altruism is built. Among the lower animals-and we must search the depths ere we exploit the shallows-parental love lasts so long as the offspring are unable to fend for themselves. When that event takes place the loving guardianship of the parent disappears and is replaced by callous indifference. The change shows the shallowness of altruism among the lower animals. Man is not exempt. The black Negro and the white Arab and Kabyle (specially when the last two are mixed with negro blood) are apparently incapable of realizing even parental love. While our troops were engaged in raiding hostile Arab camps in Mesopotamia, it was a common event for nursing mpthers to throw their babies violently away among the sand dunes, and so to free themselves from an incumbrance to rapid flight. Many millennia ago in the Far East the brachycephalic races there dwelling found that this callous conduct did not "pay." Certain slim and sly individuals, calling themselves "prophets," " soothsayers," or what not, professed to exorcise devils, heal the sick, and act as medical missioners to the community generally. These quacks, with the help of their kings and other great men, instituted an annual spring festival, the Socaea lasting five days. At this feast, which was characterized in ancient Assyria by extreme lewdness and intemperance, a King-God, the "Zoganes," was elected for the five days. During his short reign he was seemingly allowed the run of the real king's harem, from which he selected a queen. At the end of his term of office he was either hung, crucified, or burnt on a funeral pyre. By so doing he carried away with him the sins of his people, so that they started a fresh year freed from sins and innocent of crime. The mythical founder of the Babylonian empire, Ninus married Semiramis, the daughter of a fish goddess, and made her his empress. Semiramis, not satisfied with this dignity, persuaded Ninus to be the "Zoganes" at the next Socaea. He was therefore immolated on a funeral pyre so that his beautiful consort might be relieved for awhile from the burden of her many sins. Such was the scapegoat.

The Futurist Superman and his Education.

Few of us activate a tithe of our cortical brain cells during an average lifetime. Large tracts of association territory, such as the right cerebral hemispheres, are rendered useless by defective education.18 Maybe the cortical areas in the "comparatively recent" evolutional zones in the prefrontal lobes are still functionally inefficient, and are therefore rarely, if ever, called into activity. Wartime surgery shows that we only use a third of the fibres in a peripheral nerve trunk to carry on our life's work; in other words, we fail to use to its full extent the mechanism at our disposal to obtain a fuller and more complete knowledge of our surroundings than is otherwise possible. If the mentality of the coming race is to be developed, and their outlook upon the world broadened, teachers must seek to stimulate some of these dormant brain cells into healthy activity, and meanwhile they might teach the young the cult of ambidexterity!

REFERENCEs.

1 The Hunterian Oration, by Sir J. Bland-Sutton, BRITISH MEDICAL JOURNAL, vol. i, p. 275. The ana tomy was worked out by Gaskell. by Geddes and Thomson 1889 (see Nature, February 14th 1918). 4 "Seg an address by Professor G Elliot Smith. Manchester Litere "Se日 Philosophical Society, 1916; also a lecture by Professor Sherrington, Royal Institution. January 23rd, 1917. 5 Description of Xenurus unicinctus (broad-banded armadillo): Garrod, Proceedings of the Zoological Society. 1878. p. 230 . 6 See a paper by S. Bent Russell, Psychological Review, vol. xxiii, No. 3. 7 The researches of T. B. Elliott, mentioned by Sir John Bland-Sutton in the Bradshaw Lecture. BRITISH MEDICAL JoURNAL, 1917, ii, p. 609. 8 Dr. S. A Februery 220 d 19179 L Koncoroni in Society of Parma ( $I l$ Mnrgagni, July 9th, 1916). * See BRTrSH MEDICAL JodRNAL, vol. ii, Epitome, p; also The Clinic of John B. Murphy vol. viii, p. 811, "2 Euphoria (undue happiness) of of John times B. Murphy. lesions of the frontal lobes." "10 Luciani's Human Physiology, travslated by Miss Welby, 1915, vol. iii. 11 The Scapegoat, by Professor Frazer. D.C.L., 1913 (the Golden Bough Series), pp. 74, 80, 83, et aliter. 12 See Virgil's Georgics. ii. 324. ${ }^{18}$ I referred to this subject many years ago "On Lopsided Generation, or Right-handedness," Proc. Physiol., vol, ix, p. 263 .

\section{RESTORATION OF FUNCTION AFTER PENE- 'TRATING GUNSHOT WOUNDS OF THE KNEE-JOINT.}

(Preliminary Communication.)

MaJor JOHN EVERIDGE, F.R.C.S.ENG., R.A.M.C.T., With Note by

Colonel A. FULLERTON, C.M.G., A.M.S., CONBULTING SURGEON.

Those of us who are on service abroad have little oppor. tunity of studying the advance in military orthopaedics which is becoming such an important element of our organization. In the vast majority of hospitals in France beds cannot be spared for retention of cases which have arrived at the stage where restorative measures are to be adopted. This, from a surgical point of view, is most unsatisfactory, but we must bow to the inevitable.

There are certain cases where, at any rate, the com. mencement of restitution of function is advisable before evacuation to England, for reasons which I shall give. These are penetrating wounds of joints, particularly knee. joints.

It is common knowledge how successful are the imme. diate results of the present-day operative methods carried out at clearing stations and base hospitals. We have been astounded by the way in which the knee recovers from the insults it has been subjected to, and we have learned to look upon the synovial membrane of a joint as being almost as good a friend as the peritoneum. To my mind, however, there is still something wanting.

It was my habit up till the end of last year to send cases which had healed by first intention after removal of foreign bodies, etc., from the knee-joint, to England about the tenth day after operation, when all doubt as to the presence of sepsis had dispersed. My custom was to ascertain on the day of departure if there was any move. ment of the knee-joint present, and to send Medical Re. search correspondence cards with the patients, for information of progress, especially of ultimate mobility. The information was, as a rule, forthcoming, but generally brought disappointment, for, according to these reports, restoration of function was not commensurate with the immediate success of the operation.

Several factors may account for this.

1. The patient may not arrive, or arrive too late, at a home hospital where orthopaedic measures are understood and practised. It would appear that each day's delay before the carrying out of efficient movements, etc., will add very considerably to the time of ultimate recovery.

2. The psychological factor must not be ignored. It is no evidence of poor morale, but a natural consequence that a man who has become accustomed to the comforts of a home hospital, perhaps near his native city, will not be over enthusiastic to get back to the trenches, probably to a new unit. His will to recover or not to recover, where 
complete recovery means return to duty overseas, will have a large bearing on the completeness or otherwise of restoration of function. Want of co-operation is a severe hindrance in orthopaedic proceedings.

3. The personal interest of the surgeon who performs the operation is lacking when the patient is transferred. The overworked members of the profession in England can hardly be expected to put such vigour into the aftertreatment of cases which are to them second, third, or fourth hand. Moreover, fear of a flare-up-more likely, I believe, to occur in late cases where fibrous adhesions in the joint have to be broken down-may deter some of those at home from actively interfering.

Restoration of function after "civil" operations on kneejoints (removal of cartilages, wiring of the patella, etc.) are nearly always accompanied by a full range of mobility. The three factors above mentioned may account for the lack of a corresponding result in those cases of gunshot wounds where no septic complications developed, or where there was no gross lesion of the articular surfaces. It might be suggested that organizing blood effusion is more likely after gunshot wounds, but since it is the universal practice to wash out the knee-joint when performing the operation, this objection does not hold.

To help to obviate the three above deterrent factors, I have come to the conclusion that early movements should be commenced before evacuation to England, beginning, as * a rule, about the seventh day after operation. The movements are continued by easy steps until there is a range through at least 90 degrees. This range I make the necessary qualification for evacuation to England, and my patients have this explained to them very clearly, emphasis being laid on the fact that the sooner their knees can be bent to a right angle the sooner they will be sent home. As a rule, this range is obtained in seven to ten days-occasionally, but not often, longer.

I have devised an arrangement by which movements of the knee-joints may be car ried out with the minimum amount of pain to the patient and trouble to the operator. The results achieved with it are most encouraging, and have justified the time spent in construction, and the carrying out of manipulation. The essential parts of the apparatus are as follows (Fig. 1):

1. A Hinged Thomas Knee Splint.-These hinges are inserted into an ordinary Thomas splint provided with extra stout side bars. A locking device on the hinges is necessary; it is controlled either by a bolt and thumb. screw, or by locking pins inserted through holes on large flat discs welded on to the side bars. This splint is slung, but not from its extreme upper and lower ends, as is the usual practice. The cords sustaining the weight of the upper part are fixed immediately above the hinges, while the lower part is supported by cords attached to the bars about $15 \mathrm{in}$. below the hinges. Tent "runners" are used on the suspending cords for adjustments.

2. Two Overhead Rigid Bars (comparable to a double Balkan bar, differing, however, in that the bars should be $5 \mathrm{ft}$. above the level of the bed; they should extend beyond the head and foot of it, and have a considerable inclination towards the foot end). These bars are 12 in. apart, and lie over the affected limb; they carry a system of pulleys, over which run cords suspending at one end part of the splint, at the other counterbalancing sand reservoirs.
3. Sand Reservoirs.-There are four of these (Fig. 1). They were made from conical topped oil drums, the three upper ones are fixed inverted to allow easy escape of sand. The reservoir A counterpoises the lower part of the splint, and $B$ the upper. These reservoirs will have an up and down excursion according to the variation in position of the parts of the splint they counterbalance. $c$ is a sand cistern, and is fixed, while $D$ receives waste sand from $B$. Into the necks of the drums are fitted corks, perforated by three eighths inch glass tubing, connected on to which is a short length of rubber tubing. Sand will flow through these tubes, and can be controlled by paper clips, which by gripping a part of the circumference of the rubber tube will diminish the rate of flow, or will stop it altogether by complete compression.

Method of Procedure.

About the tenth day, or earlier in favourable cases, the leg to be fixed is put into the hinged splint, the joints of which have been locked, making the whole rigid. The leg extensions are tied to the crossbar of the splint in the ordinary way, and the foot suspended by gauze glued to the sole, from a metal frame. Enough sand is put into the reservoirs $A$ and $B$ to float the splint comfortably, and when the hinge locks are released to suspend the two limbs of the splint in their relative positions. The tap of the reservoir $A$ is now released, and the sand runs into $B$, the result being that slowly the splint develops an angle and the linee bends.

During the first two or three days the sand is allowed to run very slowly and no great range of move. ment should be attempted, about 45 degrees being enough. After this the patient will have gained confidence, will realize the object aimed at, and will co-operate. The time taken is about half an hour; after this a return to the original position is obtained by allow. ing sand from $B$ to run into the waste receiver $D$; thus the upper part of the splint descends; the lower part is raised by running sand from the cistern $\mathrm{C}$ into $\mathrm{A}$. When a comfortable position and height of the limb is gained, the linges are locked.

It is advisable, in refractory cases, where progress is slow, to lock the hinge at the limit position of flexion obtained at the end of the sitting. It may be so left for a few hours, and in this way it may be fixed at a slightly smaller angle each day.

As a rule, at the end of a week the patient is able, and often anxious, to begin active movements. These are to be encouraged, and if he can be sent home with a range of active movement through a right angle, and without a splint, he is unlikely ever to stiffen up again. At this stage walking appears to be unattended with harmful results. It is of great advantage to carry out a course of massage, faradism, and movements (active, passive, and resisted) when flexion through 90 degrees has been obtained, thereby hastening the time of full recovery.

When the man is evacuated to England it is cleariy stated on his field card what range of movement was obtained when he left France, and an appeal is made for progressive treatment. This is, no doubt, superfluous in many cases, but not in all, for quite recently $\dot{I}$ have received reports in the following tone: "No sepsis, transferred to back splint, moved occasion. ally," and "Put on back splint, knee ankylosed." Some patients have written to me that they have had no 
movements carried out, and that their knees have become stiff.

Such were some of the ultimate results of cases which liad healed by first intention, showed no signs of subse quent sepsis, and should have obtained good movable joints, before I instituted my present method of procedure. Of seven cases which liealed by primary union after arthrotomy in October, 1917, the best results I have knowledge of are (1) 25 degrees of movement, (2) 10 to 15 degrees, (3) four-fifths of full mobility. The last is the only one of these seven who, apparently, has been returned to his dépôt for duty.

Advantages Claimed for this Procedure.

1. The movements, being so insidious, are nearly painless.

2. Painless movements do not set up reflex spasm.

3. Movements can be commenced early and prevent fixation due to intra-articular or extra-articular fibrosis.

4. Elimination of the danger of acute flare-up, as may happen when forcible movements are carried out under anaesthesia.

5. Where masseuses are not available, a nurse or intelligent orderly may carry out the treatment. A number of cases may be treated at the same time.

6. The patients are informed that the qualification for England is that their knees shall bend to a right angle. This encourages their best endeavours-a factor of incalculable value in all orthopaedic measures.

7. The apparatus is cheap and can be set up by any one mechanically inclined. The necessary material may be collected in almost any camp hospital on the lines of com. munication or at the base.

I have been tempted to adopt the principles outlined above to prevent stiffness of knees occurring during the treatment of fractured femurs. With the present-day methods we can, as a rule, obtain good alignment and little or no shortening. Fractures of the lower and middle third, lowever, are nearly always followed by limitation of knee movement, especially where the usual method of leg extension is adopted. The stiffness has in most cases an extra-articular source; it results from cicatrization of the traumatic and operation wounds, and is accentuated in cases where there is prolonged suppuration. Can we not prevent this stiffness of the knee from becoming established?

When acute sepsis has subsided, good alignment procured, and the fractured ends are becoming "sticky," I have tried this method of knee flexion with encouraging results. Firm support at the seat of fracture in addition to extension is imperative.

Example.-Pte. C., comminuted fracture of lower third of left femur, December 5th, 1917. Two days later I removed a large piece of high explosive, one loose fragment of bone, and applied bipp to the exposed muscles. On January 22nd, 1918, the bones were "sticky" and movements commenced. He was sent to England early in March with a range of movement from complete extension to considerably less than a right angle.

I am not equipped with a sufficient number of results to be able to state dogmatically that this method is advisable. However, the few cases I have treated encourage me to further trials.

It appears that early institution of movement after penetrating gunshot wounds of the knee may determine whether or not the wounded man will become fit again for military service. It seems justifiable to postpone evacuation to England for a week or two in order to adopt measures which yield prospects of at length getting men back to duty, or at any rate making them more fit for subsequent civil employment.

Since writing the above $I$ have learnt that Willems has for some time advocated mobilization of knee-joints immediately after operation. He commences active movements from the very first, and claims an early return of full. range mobility in most cases, even where there is considerable bone injury. Not uncommonly there is an effusion of blood into the joint which checks progress; lowever, when this is drawn off, movements make good headway, and walking is usually possible in the second or third week. He is not deterred from carrying out active movements even in the presence of suppuration, holding that the movements express pus from the recesses of the joint through the incisions made for drainage.
Such treatment is somewhat revolutionary, but, after all, many of our pre-war ideas have had to undergo an upheaval equally dramatic.

Note by Colonel Fullerton, C.M.G., A.M.S.

The difficulties encountered in obtaining a freely move. able joint in wounds of the knee and in fractures of the lower third of the thigh are notorious. Most massage operators are inclined to be too brusque in their endeavours to obtain joint movement.

Major Everidge has devised a plan by means of which a graduated range of movement may be calculated with almost mathematical precision. The insidious coaxing into function accomplished by his method prevents the painful spasm and the lighting up of infection which is so liable to accompany unmeasured attempts by even the gentlest manual manipulation. I have watched most of his cases with interest during the earliest periods of their convalescence, and I have been struck by the absence of febrile reaction and pain.

The method is scientific, and has proved successful in the cases I have been able to follow with him.

It is to be hoped that surgeons at home who see cases of injured knee-joint and fractured lower third of the femur will be encouraged by Major Everidge's success to persevere with this or similar methods, to avoid what has hitherto been somewhat of a reproach in war surgery.

\section{SUGGESTIONS FOR THE TREATMENT OF SEPTIC WOUNDS.}

$$
\text { BY }
$$

FREDERICK W. ROBINSON, M.B., F.R.C.S. Late Captain R.A.M.C.

CONGULTING SURGEON HODDERSFIELD ROXAL INFIRMARY.

THE following paper deals with the impressions derived from an analysis of a thousand cases which passed through the writer's hands at an auxiliary hospital. These cases were taken in rotation and not by selection. They were all in a more or less convalescent stage, having been treated at various hospitals, so that in the majority of cases many months had elapsed from the commencement of their illness to the time of their admission to the auxiliary. hospital.

There was of necessity some finality in their sym. ptoms as shown in a depreciation of their potential capacity as soldiers. The symptoms, too, were more or less dissipated and attenuated, and in this sense possessed a value of their own as enabling them to be more easily classified and their importance appreciated. The constant association of neurasthenia with other diseases, such as frost-bite, rheumatism, wounds, gas poisoning, tended to show how the ordinary symptoms of these diseases could be materially modified, and that chiefly in the direction of persistence and exaggeration.

The majority of cases of neurasthenia were sent as cases of "shell shock," but however much the symptoms may have approximated to those of shock in the initial stages, at the time they were admitted into our hospital they were undoubtedly neurasthenic, representing a condition of cerebral and spinal exhaustion. For instang a condition of cerebral of unconsciousness for some days following a bursting shell; another had a history of prolonged mental and physical strain in the trenches, yet in both these cases the symptoms were identical. In every case noted as neurasthenia there was some gross manifestation of the disease, though the cases of a milder degree not noted must have been manifold. Some symptoms which are generally regarded as casual or ordinary in the neurasthenia, traumatic or otherwise, met with in civil practice become dominant features in these shell-shock cases. Such, for instance, are tachycardia, stammering, tremors, which are far more in evidence in these cases.

In the 1,000 cases analysed, 75 were neurasthenic, while 505 were the subjects of wounds; of the latter, 249 suffered from disability owing to pain, limited movements, and deformity. Of these latter, all complicated with fracture were excluded. The disability was entirely due to scar defects. These scars were distinguished by their multiplicity in individual cases and by the large number that were adherent, irregular, and infiltrated. There was a marked contrast between the scars in these cases and the scars met with in the South African war, the propor. tion of cases producing disability being much larger. 'This 